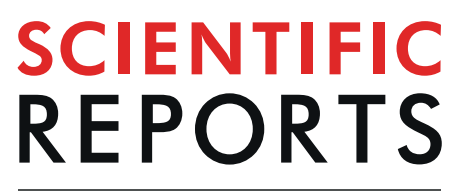

natureresearch

Check for updates

\title{
A promising and cost-effective biochar adsorbent derived from jujube pit for the removal of $\mathrm{Pb}$ (II) from aqueous solution
}

\begin{abstract}
Junkai Gao, Yu Liu, Xuebin Li, Mouyuan Yang, Jinbao Wang ${ }^{\varpi}$ \& Yan Chen
This study evaluated the $\mathrm{Pb}$ (II) sorption capacity of jujube pit biochar (JPB) in aqueous solution, which was derived from jujube pit by pyrolysis and used as a promising and economical adsorbent. More importantly, the utilization of JPB could realize the recycling of agricultural residues. The JPB was characterized using conventional science technologies, including SEM, BET and FT-IR, and the sorption capacity of JPB for lead ions was investigated according to different adsorption parameters, such as the kinetics data, solution $\mathrm{pH}$, isotherms data, coexisting ions of $\mathrm{Na}^{+}$and $\mathrm{K}^{+}$, desorption and reusability, and solution temperature. The results of kinetics data suggested that the lead ion adsorption process by JPB could be fast to reach equilibrium within $30 \mathrm{~min}$. Additionally, the adsorption capacity of JPB for $\mathrm{Pb}$ (II) was calculated to be maximum for $137.1 \mathrm{mg} / \mathrm{g}$ at pH 6.0. More importantly, after five cycles of desorption and reuse, the JPB still reached $70 \%$ of its original adsorption capacity. All the results suggested that JPB had a broad application prospect for the purification of lead ions in practical.
\end{abstract}

$\mathrm{Pb}$ (II) has serious contamination with toxicity in aqueous soulution ${ }^{1}$ that is extremely harmful to human health ${ }^{2-4}$. Removing lead ions from wastewater has become an important task for humans. To date, some physical and chemical technologies, such as electrodialysis ${ }^{5}$, flocculation ${ }^{6}$, ion exchange ${ }^{7}$, chemical precipitation ${ }^{8}$, membrane filtration ${ }^{9}$ biosorption ${ }^{10}$ and adsorption ${ }^{11}$, have been applied to remove lead ions. Among all these purification strategies, adsorption is a promising and attractive method because the operation process for adsorption is simple, the operation cost is low and the possibility of secondary pollution is minimal ${ }^{12}$. According to previous research, different types of adsorbents, such as montmorillonite ${ }^{13}$, bionanocomposite ${ }^{14}$, activated carbon ${ }^{15}$, activated carbon fiber ${ }^{16}$, coal $^{17}$, periwinkle shells ${ }^{18}$, and nanocomposite ${ }^{19}$, have been used for metal ions adsorption. The conventional adsorbent material, activated carbon, is widely used in wastewater purification and has attracted remarkable attention for considerable adsorption capacity and complex pore structure. However, traditional activated carbons have some defects, namely, a high fabrication cost and low reusability ${ }^{20}$. Therefore, research on carbon-based adsorption materials with high adsorption performance and low cost is of great importance and practical application value.

Biochar is a carbon material with abundant pores that is derived from biomass and prepared by pyrolysis. The merits of considerable adsorption capacity, a low preparation cost and an easy preparation process have made biochar adsorbents a current research focus ${ }^{21}$, and various kinds of biochar have been used as adsorption materials to remove $\mathrm{Pb}(\mathrm{II})$. Lee et al. measured the sorption capacity of GB (gingko leaf biochar), $\mathrm{PB}$ (peanut shell biochar) and $\mathrm{MB}$ (Metasequoia leaf biochar) for lead ions, and the results showed that the adsorption capacities of lead ions by GB, MB, and $\mathrm{PB}$ were $138.89,34.01$, and $30.67 \mathrm{mg} / \mathrm{g}$, respectively ${ }^{1}$. Shen et al. studied the adsorption capacity of $\mathrm{Pb}(\mathrm{II})$ by rice straw biochars that were prepared by using the pyrolysis method at $300^{\circ} \mathrm{C}, 500^{\circ} \mathrm{C}$ and $700^{\circ} \mathrm{C}$, and the adsorption capacities were $109.59,153.81$ and $171.34 \mathrm{mg} / \mathrm{g}$, respectively ${ }^{22}$.

Jujube is distributed in subtropical and temperate regions and possesses value as a food and nutriment due to its therapeutic properties ${ }^{23,24}$. Jujube pit is considered a byproduct of agricultural waste and is usually thrown away directly after the jujube flesh is extracted. Jujube pits are abundant and easy to collect in China and have several excellent characteristics for clear natural structure, low ash content and hardened lignocellulosic composition, which make jujube pits become a reasonable raw material for the preparation of biochar ${ }^{25,26}$. 


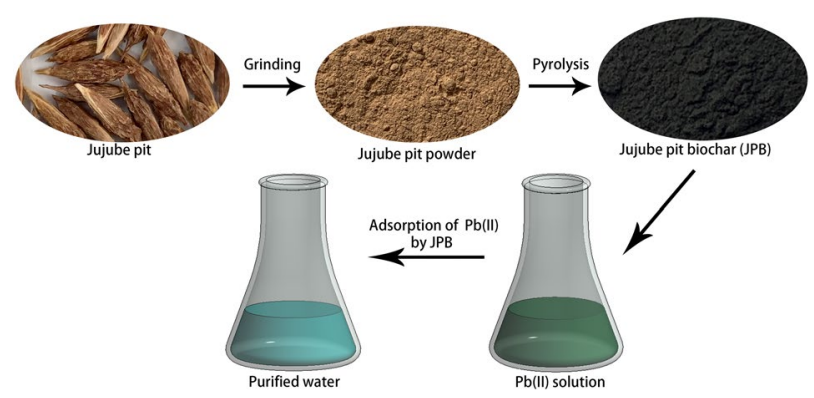

Figure 1. Preparation and utilization procedure of JPB.

In the present work, JPB was synthesized using jujube pit as the raw material by a simple pyrolysis method, which has the merits of cost effectiveness and ease of operation. The preparation and utilization procedure of JPB was shown in Fig. 1. Because the JPB was derived from a byproduct of agriculture, the utilization of JPB could realize the recycling of agricultural residues. The properties of the prepared JPB were characterized by SEM for surface structure, FT-IR for basic chemical groups, and BET for pore distribution and particle diameter size. The adsorption behavior of lead ions by JPB was studied including contact time, lead ion concentration, $\mathrm{pH}$, coexisting ions and solution temperature, respectively. In addition, the reusability of JPB for lead ion removal was investigated in order to estimate its adsorption capacity after several cycles. According to the experimental results, the JPB usded as a novel adsorbent for lead ion adsorption was favorable, and therefore, JPB has the potential to be a promising and cost-effective biochar adsorbent for removing lead ions in practical applications.

\section{Materials and methods}

Experimental materials. The jujube pits were obtained from jujubes obtained from Hetian, Xinjiang, China. Lead nitrate used for the preparation of lead ion solutions was produced by Sinopharm Chemical Reagent Co. Ltd. L-Ascorbic acid was bought from Sinopharm Group Chemical Reagent Co. Ltd. Potassium ferrocyanide trihydrate and ammonium fluoride were purchased from Shanghai Macklin Biochemical Co. Ltd. Thymol blue and xylenol orange tetrasodium salt were obtained from Aladdin Industrial Corporation, and sodium acetate buffer solution was purchased from Sigma-Aldrich.

Preparation of jujube pit biochar. JPB was synthesized using jujube pit as the raw material. First, the residual pulp impurity on the surface of the jujube pit was removed by brushing. Then, the jujube pit was washed for its surface residues with distilled water and then dried at $105^{\circ} \mathrm{C}$ for a whole day $(24 \mathrm{hrs})$. After that, the clean and dry jujube pits were broken into powder by a high-speed disintegrating machine (Zhejiang Hongjingtian Industry and Trade Co. Ltd), and then the powder was sieved through a standard sample sieve (Taizhou Yueyang Trading Co. Ltd) with a size of 200 mesh per inch. The selected jujube pit powder was pyrolyzed at $800^{\circ} \mathrm{C}$ for two hours under a nitrogen atmosphere in a tubular furnace to obtain JPB.

Lead ion adsorption. In batch sorption experiments, the room temperature was approximately $298 \mathrm{~K}$, and the solution $\mathrm{pH}$ was 6 , which was adjusted by $0.1 \mathrm{M} \mathrm{HNO}_{3}$ or $\mathrm{NaOH}$. A total of $0.01 \mathrm{~g} \mathrm{JPB}$ powder was added to $25 \mathrm{~mL}$ lead ion solution for mixture, and then the mixture was placed into a shaker (THZ-98A, Shanghai Yiheng Scientific Instrument Co., LTD, China) and stirred for a certain time. After that, the mixture was removed and then separated by a vacuum pump for filtration. Each experiment was carried out using two parallel samples, and if the error between the test results of the two parallel samples was less than five percent, the test results would be adopted. While the whole adsorption process was completed, the concentration of lead ions in the solution was measured by a visible spectrophotometer (723), which was made by Shanghai Jinghua Technology Co., LTD.

The adsorption quantity of lead ions by JPB was obtained according to the adsorption balance Eqs. (1) and (2), where $\mathrm{q}_{\mathrm{t}}(\mathrm{mg} / \mathrm{g})$ is the quantity of lead ions adsorbed by JPB when the experiments are conducted for $\mathrm{t}$ min and $\mathrm{q}_{\mathrm{e}}(\mathrm{mg} / \mathrm{g})$ is the equilibrium adsorption capacity.

$$
\begin{aligned}
& q_{t}=\frac{\left(c_{0}-c_{t}\right) \cdot v}{m} \\
& q_{e}=\frac{\left(c_{0}-c_{e}\right) \cdot v}{m}
\end{aligned}
$$

In Eqs. (1) and (2), $C_{0}, C_{e}$, and $C_{t}(\mathrm{mg} / \mathrm{L})$ are the concentration of lead ions in solution at the beginning, time $t$, and equilibrium, respectively; $\mathrm{V}$ is the volume of lead ions in solution $(\mathrm{L})$; and $\mathrm{m}$ is the dry JPB quantity (g). Each adsorption experiment was performed twice, and the experimental data are reported as average values.

Effect of $\mathrm{Na}^{+}$and $\mathrm{K}^{+}$. In batch sorption experiments, the solution temperature and the $\mathrm{pH}$ were $298 \mathrm{~K}$ and 6.0, and meanwhile, $\mathrm{NaNO}_{3}$ was used as the presence of $\mathrm{Na}^{+}$and $\mathrm{KNO}_{3}$ was used as the presence of $\mathrm{K}^{+}$, respectively. Additionally, the concentration of $\mathrm{Na}^{+}$or $\mathrm{K}^{+}$ions were set up for $0,0.1,0.2,0.3,0.4$ and $0.5 \mathrm{~mol} / \mathrm{L}$. In these experiments, the concentration of prepared $\mathrm{Pb}(\mathrm{II})$ solution was $150 \mathrm{mg} / \mathrm{L}$. 


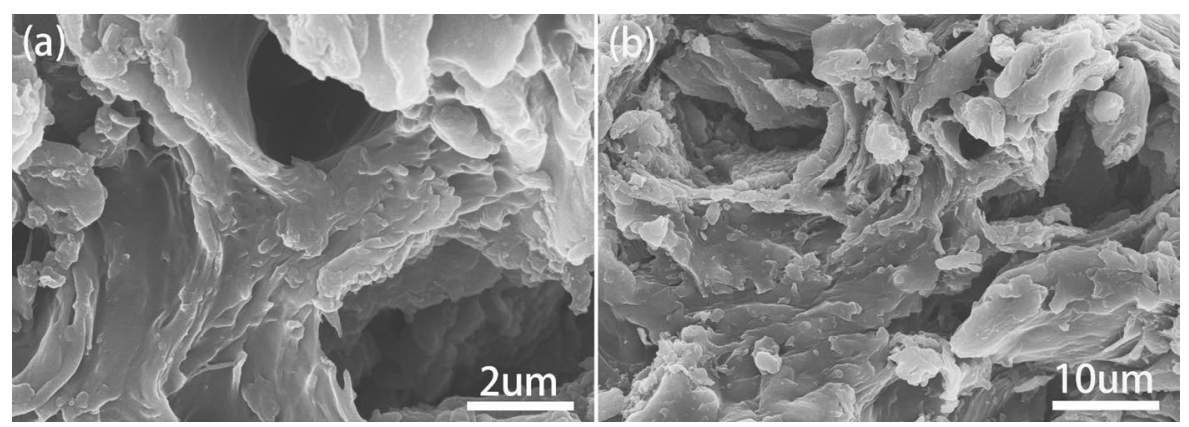

Figure 2. SEM images of JPB.

Effect of temperature. The operating temperature was in a range from $298 \mathrm{~K}$ to $308 \mathrm{~K}$, and the solution $\mathrm{pH}$ was 6 . The prepared $\mathrm{Pb}(\mathrm{II})$ concentration for the batch experiments was $150 \mathrm{mg} / \mathrm{L}$, and the adsorbent dosage was $400 \mathrm{mg} / \mathrm{L}$.

Desorption and reusability experiments. The reusability experiments were conducted by placing $10 \mathrm{mg}$ JPB powder in a conical flask mixed with $25 \mathrm{ml}$ lead ion solution $(100 \mathrm{mg} / \mathrm{L})$; the temperature and pH were $298 \mathrm{~K}$ and 6.0, respectively. Then, the mixture containing JPB adsorbent and lead ions was stirred in a shaker at $200 \mathrm{rpm}$ for $90 \mathrm{~min}$. After that, the mixture was filtered to separate the JPB adsorbent, the lead ion concentration in the filtered solution was tested, and then the adsorption quantity of lead ions by JPB could be calculated. Then, the spent JPB samples were regenerated using $0.2 \mathrm{M}$ hydrochloric acid and washed using distilled water followed by drying $^{26}$, after which the regenerated JPB was used in the following adsorption cycle.

Characterization of raw material (jujube pit) and biochar (JPB). Surface morphological images of JPB particles were detected using a scanning electron microscope (SEM, FEG-250, FEI, USA). The chemical structures of jujube pit powder and JPB were both analyzed by Fourier transform infrared spectroscopy (FTIR, VECTOR22, Bruker, Germany). The Brunauer-Emmett-Teller (BET, NOVA 2000e, Quantachrome, America) method was used for accurate calculation of the specific surface area of JPB, and the pore size distribution was specifically analyzed using the $\mathrm{BJH}$ method based on the nitrogen adsorption-desorption isotherms. Before the nitrogen adsorption-desorption process, JPB powder samples were dried at $323 \mathrm{~K}$, and $0.1 \mathrm{~g}$ samples were added into the sample tube, which was then putted into the degassing station to degas, and the degassing temperature was $77.3 \mathrm{~K}$.

\section{Results and discussion}

Characterization of JPB. SEM images of the jujube pit biochar are shown in Fig. 2. Several distinct characteristics were apparent on the JPB surface. A plenty of clear irregular wrinkles were covered on the JPB surface, while a lamellar nature and significant roughness were also observed from the images. Additionally, carbon-based functional groups contribute to the roughness on the surface of $\mathrm{JPB}^{4}$. Such surface morphology structures possess many advantages ${ }^{27}$. For example, the wrinkled surface of JPB could make its surface area enlarged and make more active and adsorbable sites exposed on the outside ${ }^{28}$, which could make a promotion for lead ions adsorbed onto the JPB surface more easily ${ }^{29}$.

The curve of nitrogen adsorption-desorption isotherms is presented in Fig. 3. The JPB possessed a lot of small dispersed pores, which caused some nitrogen to leave in the sample pores during desorption contributing to the lack of closure in the adsorption/desorption isotherm ${ }^{30}$. And the graph of pore size distribution of JPB are presented in Fig. 4., respectively. The average pore diameter and surface area of JPB were $3.387 \mathrm{~nm}$ and $246.9 \mathrm{~m}^{2} / \mathrm{g}$, respectively, while the test result for pore volume was tested to be $0.054 \mathrm{~m}^{3} / \mathrm{g}$. The large surface area could contribute to interactions between the adsorption sites of JPB and lead ions ${ }^{31}$. Moreover, the pores were large enough for lead ions to enter the inner surface of JPB, and hence, its adsorption capacity could be enhanced ${ }^{31}$.

The FTIR spectra of the JPB and the raw material (jujube pit) are shown in Fig. 5. In these spectra, the intensity of the peaks at 852,1400 , and $1470 \mathrm{~cm}^{-1}$ for JPB decreased and the intensity of the peaks at 1630 and $3470 \mathrm{~cm}^{-1}$ increased after pyrolysis. The band at $852 \mathrm{~cm}^{-1}$ could be ascribed to the weak stretching vibration of aromatic $\mathrm{C}-\mathrm{C}^{22,32}$. In the jujube pit spectrum, the bands observed at $1400 \mathrm{~cm}^{-1}$ and $1470 \mathrm{~cm}^{-1}$ originated from the strong stretching vibration of $\mathrm{C}-\mathrm{H}$ in alkanes or alkyl groups and $\mathrm{C}=\mathrm{O}$ in carboxyl groups, respectively. After pyrolysis, the two peaks disappeared in the spectrum of JPB, which was attributed to the decomposition of cellulose and hemicellulose ${ }^{22}$. Moreover, the peak detected at approximately $1630 \mathrm{~cm}^{-1}$ resulted from the stretching vibration of $\mathrm{C}=\mathrm{C}^{25}$. The peak at $3470 \mathrm{~cm}^{-1}$ was assigned to hydroxide $(-\mathrm{OH})$ stretching, and the hydroxyl groups were mainly from carboxylic acids and some of the water in the detected samples ${ }^{33}$.

Sorption kinetics. Contact time is a significant parameter for evaluating sorption kinetics in adsorption processes. The change in the adsorption amount of $\mathrm{Pb}$ (II) on JPB is depicted in Fig. 6. In this experiment, the concentration of $\mathrm{Pb}(\mathrm{II})$ was $150 \mathrm{mg} / \mathrm{L}$, and the solution $\mathrm{pH}$ was set to 6 . The adsorption process could reach equilibrium after 30 minutes of reaction, and it could be divided into three different stages for analysis. In the first stage, the adsorption capacity of $\mathrm{Pb}$ (II) by JPB increased rapidly in the initial fifteen minutes, and the adsorption amount reached $62.5 \mathrm{mg} / \mathrm{g}$, which was $80 \%$ of the saturated adsorption capacity. The rapidly increasing 


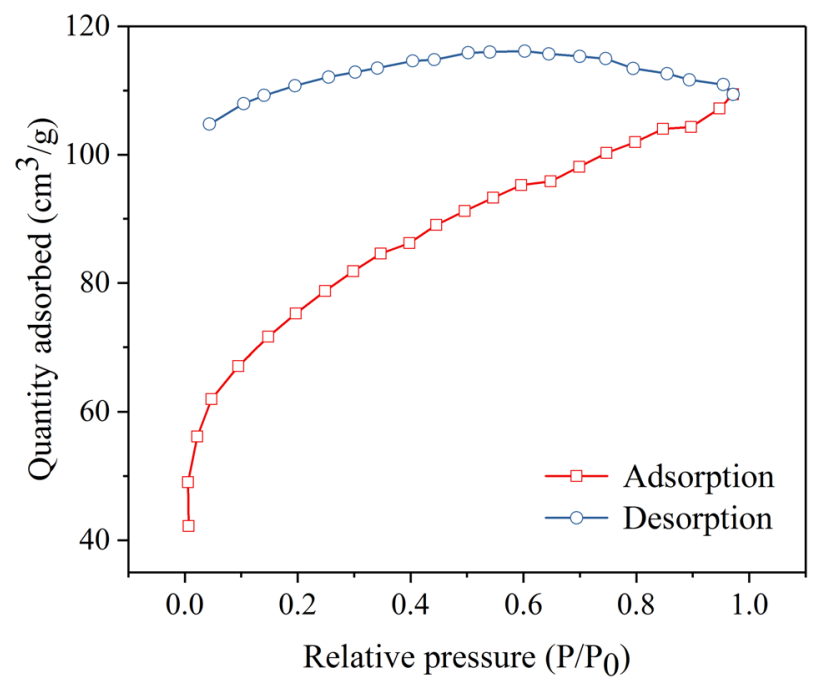

Figure 3. Nitrogen adsorption/desorption isotherms of JPB.

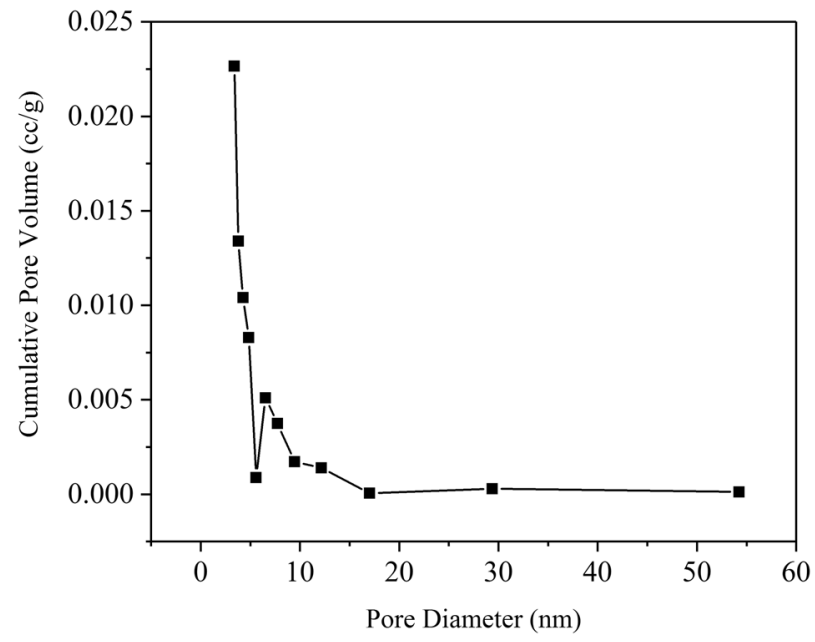

Figure 4. Pore size distribution of JPB.

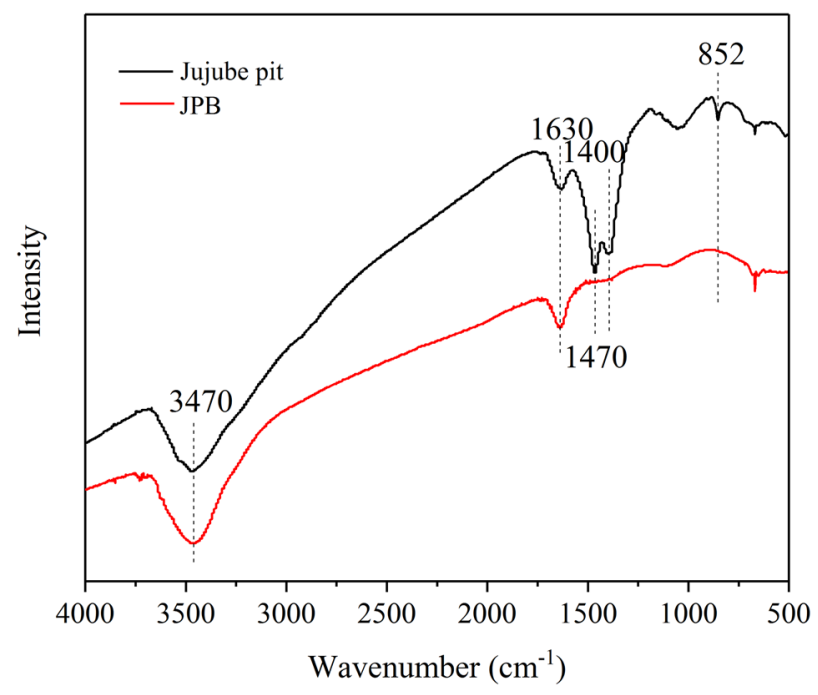

Figure 5. FT-IR spectra of jujube pit and JPB. 


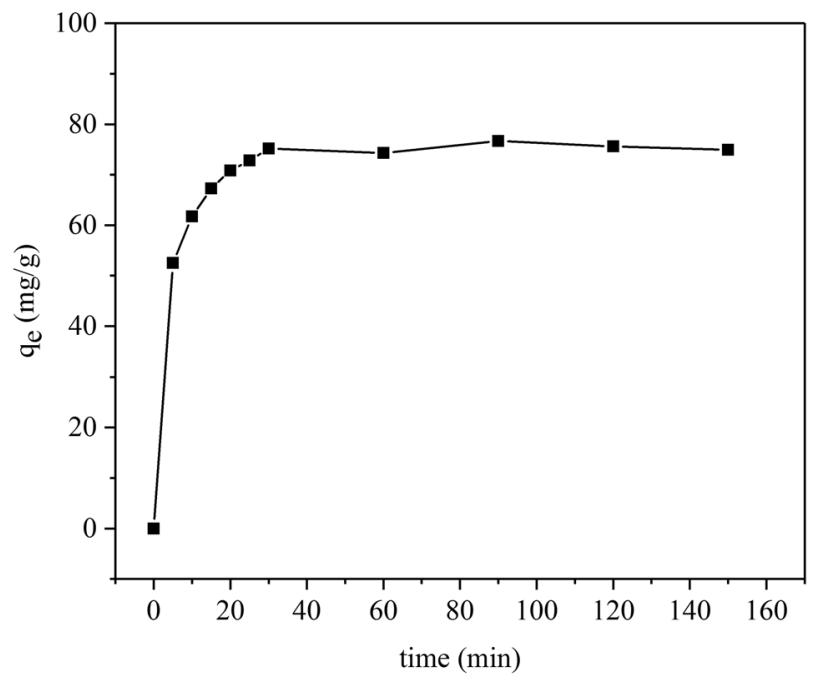

Figure 6. Effect of contact time on $\mathrm{Pb}(\mathrm{II})$ adsorption on $\mathrm{JPB}$.

adsorption amount for the first period was primarily owing to the abundant vacant sites exposed on biochar, which could contribute to making the lead ions attached onto the surface of JPB easily ${ }^{4}$. Moreover, the higher concentration gradient made $\mathrm{Pb}$ (II) rapidly adsorbed by the JPB. The second stage was the next $15 \mathrm{~min}$; the adsorption capacity could still increase, but the increasing speed became much slower than that during the first stage, and the adsorption capacity gradually became close to the saturated value. In the last stage, the adsorption amount was maintained at a relatively stable value, which suggested that the adsorption equilibrium was reached and the amount would not change with the reacting time changing. Based on the study results, the adsorption equilibrium of $\mathrm{Pb}(\mathrm{II})$ on $\mathrm{JPB}$ could be achieved sufficiently in $30 \mathrm{~min}$.

Three classical kinetics models were utilized to study the adsorption procedure and rate of $\mathrm{JPB}$ for $\mathrm{Pb}$ (II) removal, including pseudo-first-order ${ }^{34}$, pseudo-second-order ${ }^{35}$ and Elovich kinetic equations ${ }^{25}$, which can be presented as:

$$
\begin{gathered}
\ln \left(q_{e}-q_{t}\right)=\ln q_{e}-k_{1} \cdot t \\
\frac{t}{q_{t}}=\frac{1}{k_{2} q_{e}^{2}}+\frac{t}{q_{e}} \\
q_{e}=\frac{1}{\beta} \ln t+\frac{1}{\beta} \ln (\alpha \beta)
\end{gathered}
$$

where the adsorption rate constant of pseudo-first-order model is represented as $\mathrm{k}_{1}\left(\mathrm{~min}^{-1}\right)$, the adsorption rate constant of pseudo-second-order is represented as $\mathrm{k}_{2}(\mathrm{~g} /(\mathrm{mg} \cdot \mathrm{min}))$, $\mathrm{q}_{\mathrm{t}}$ is the lead ion adsorption quantity after the experiment is conducted for $\mathrm{t} \min$ and $\mathrm{q}_{\mathrm{e}}$ is the amount when the adsorption experiment reaches equilibrium, $\alpha$ is the initial adsorption rate $(\mathrm{mg} /(\mathrm{g} \mathrm{min}))$ and $\beta$ is a constants for desorption constant $(\mathrm{g} / \mathrm{mg})$.

The linear relationship of the kinetic models was shown in Fig. 7. The relevant parameters of the kinetic equations were exhibited in Table 1. By analyzing and comparing the experimental data in Table 1, an unreasonable experimental adsorption capacity $\mathrm{q}_{\mathrm{e}}$ was predicted by pseudo-first-order kinetic and Elocich kinetic model due to the significantly lower $\mathrm{R}^{2}$ value, indicating that these models provided an improper fit to the sorption kinetics. In contrast, the pseudo-second-order model with a correlation coefficient $\left(\mathrm{R}^{2}\right)$ approaching to 1 was proved to be more appropriate to fit the kinetics model, and the calculated value of $\mathrm{q}_{\mathrm{e}}(83.3 \mathrm{mg} / \mathrm{g})$ was closer to the actual adsorption capacity $(75.2 \mathrm{mg} / \mathrm{g})$ obtained from the experiment than that calculated from the pseudo-first-order model. Therefore, the applicability to the adsorption process of $\mathrm{Pb}$ (II) on JPB was better to be described by pseudo-second-order model.

Adsorption isotherm. The adsorption amount of the adsorbent for various concentrations at a fixed temperature is shown by the adsorption isotherm. Relevant experiments were conducted with ambient temperature for $298 \mathrm{~K}$, meanwhile the $\mathrm{Pb}(\mathrm{II})$ concentrations ranged from 30 to $150 \mathrm{mg} / \mathrm{L}$ and the solution was in the condition of faintly acid for the $\mathrm{pH}$ was 6.0. The adsorption result is displayed in Fig. 8. The data revealed that as the concentration of $\mathrm{Pb}(\mathrm{II})$ increased, the increased rate of adsorption amount slowed down gradually, progressively saturating the adsorbent ${ }^{36}$.

Three different isotherm models (Langmuir, Freundlich and Tempkin) were used to study the maximum adsorption capacity, and the models are expressed as Eqs. (6-8), respectively ${ }^{25,37,38}$ : 

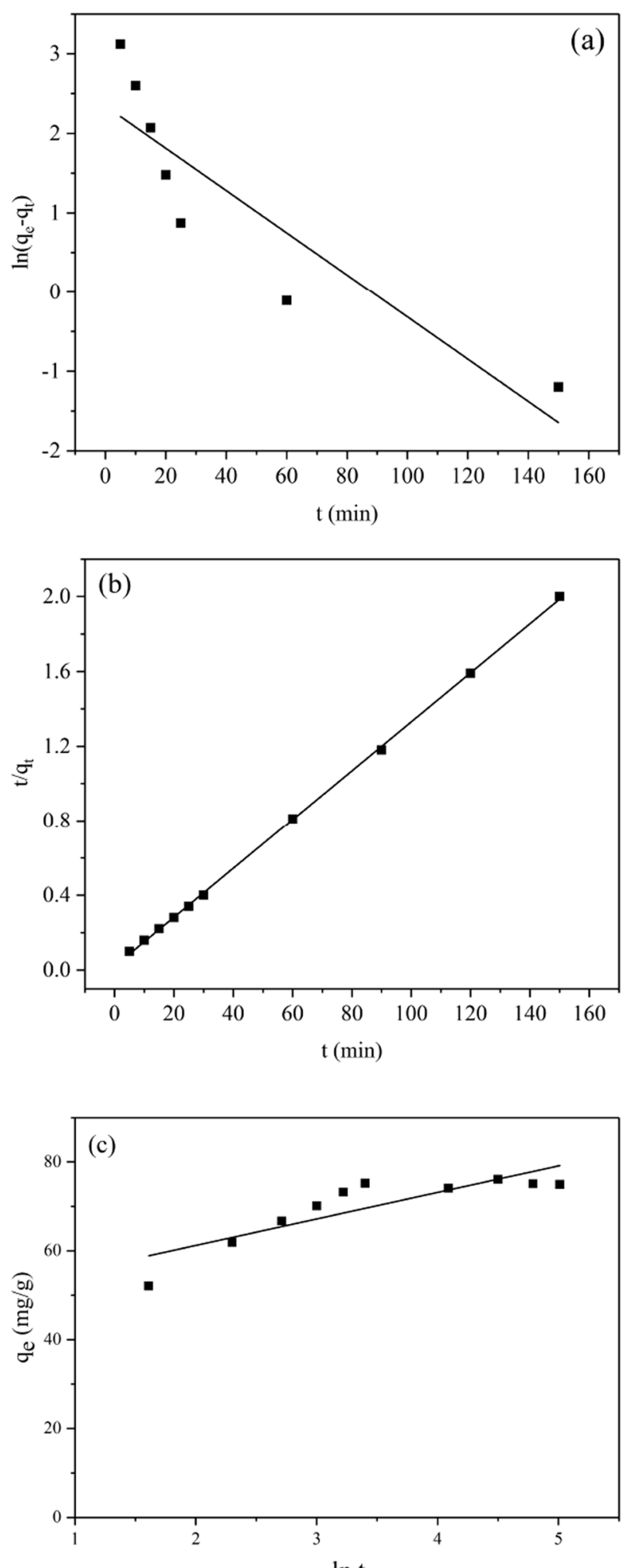

Figure 7. (a) Pseudo-first-order kinetic model, (b) pseudo-second-order kinetic model and (c) Elovich kinetic model for $\mathrm{Pb}(\mathrm{II})$ adsorption on JPB.

$$
\frac{C_{e}}{q_{e}}=\frac{1+C_{e} K_{L}}{q_{m} K_{L}}
$$




\begin{tabular}{|l|l|l|}
\hline Model & Parameter & Value \\
\hline \multirow{4}{*}{ Pseudo-first-order } & $\mathrm{K}_{1}\left(\mathrm{~min}^{-1}\right)$ & 0.026 \\
\cline { 2 - 3 } & $\mathrm{q}_{\mathrm{e}}(\mathrm{mg} / \mathrm{g})$ & 10.38 \\
\cline { 2 - 3 } $\mathrm{R}^{2}$ & 0.800 \\
\hline \multirow{4}{*}{ Pseudo-second-order } & $\mathrm{K}_{2}(\mathrm{~g} /(\mathrm{mg} \cdot \mathrm{min}))$ & 0.04 \\
\cline { 2 - 3 } & $\mathrm{q}_{\mathrm{e}}(\mathrm{mg} / \mathrm{g})$ & 83.3 \\
\cline { 2 - 3 } $\mathrm{R}^{2}$ & 0.999 \\
\hline \multirow{3}{*}{ Elovich } & $\alpha(\mathrm{mg} /(\mathrm{g}$ min $))$ & 143.1 \\
\cline { 2 - 3 } & $\beta(\mathrm{mg} / \mathrm{g})$ & 0.077 \\
\cline { 2 - 3 } & $\mathrm{R}^{2}$ & 0.71 \\
\hline
\end{tabular}

Table 1. Relevant adsorption parameters kinetic models.

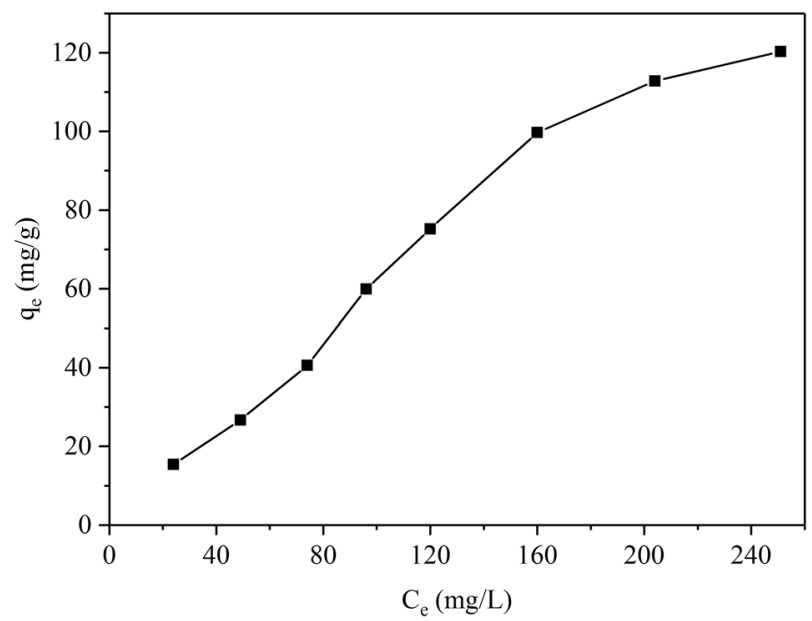

Figure 8. Sorption isotherms of $\mathrm{Pb}(\mathrm{II})$ on $\mathrm{JPB}$.

$$
\ln q_{e}=\ln K_{f}+\frac{1}{n} \ln C_{e}
$$

where $\mathrm{q}_{\mathrm{e}}$ represents the equilibrium adsorption capacity of lead ions adsorbed by a unit mass of JPB adsorbent, $\mathrm{q}_{\mathrm{m}}$ represents the maximum mass of lead ions adsorbed by a unit mass of JPB adsorbent, $\mathrm{C}_{\mathrm{e}}$ represents the concentration of $\mathrm{Pb}(\mathrm{II})$ at the time of equilibrium, and $\mathrm{K}_{\mathrm{f}}$ and $\mathrm{n}$ are two other constants.

$$
q_{e}=\frac{R T}{b T} \ln C_{e}+\frac{R T}{b T} \ln K_{T}
$$

where $\mathrm{B}_{\mathrm{T}}=\mathrm{RT} / \mathrm{b}_{\mathrm{T}}(\mathrm{J} / \mathrm{mol})$ is the Temkin constant, $\mathrm{K}_{\mathrm{T}}(\mathrm{L} / \mathrm{g})$ is the adsorption capacity and $\mathrm{R}(8.314 \mathrm{~J} / \mathrm{mol} \mathrm{K})$ is the universal constant and $\mathrm{T}(\mathrm{K})$ is the absolute temperature.

The fitted curves according to the three classic models are presented in forms of linear relationship in Fig. 9., and relevant experimental data obtained from the adsorption isotherms are exhibited in Table 2. Comparing the coefficients demonstrated that the Freundlich model $\left(\mathrm{R}^{2}=0.987\right)$ could describe the applicability to the isotherm better than the Langmuir model $\left(\mathrm{R}^{2}=0.317\right)$ and the Tempkin model $\left(\mathrm{R}^{2}=0.9249\right)$, and the calculated adsorption capacity using the Freundlich model $(137.1 \mathrm{mg} / \mathrm{g})$ was approaching to the experimental amount obtained from the experiment $(120.7 \mathrm{mg} / \mathrm{g})$ fairly. Additionally, the Freundlich equation suggested that the process of lead ion adsorption on JPB was multilayer adsorption in a heterogeneous system ${ }^{36,39}$. More importantly, the comparison between the adsorption capacities of JPB and other adsorbents was exhibited in Table 3, which suggested that the performance of JPB was favourable and competitive, and therefore, the JPB developed in this study had a broad application prospect for the purification of lead ions.

Effect of $\mathrm{pH}$. The $\mathrm{pH}$ is a significant adsorption parameter that has several distinct impacts on the efficience of metal ions removal, and since a precipitate is formed when $\mathrm{Pb}(\mathrm{II})$ is under alkaline conditions, a series of experiments were carried out in acidic conditions at $298 \mathrm{~K}$. In addition, the solution $\mathrm{pH}$ was adjusted accurately by $\mathrm{HNO}_{3}$ solution $(0.1 \mathrm{M})$ and $\mathrm{NaOH}$ solution $(0.1 \mathrm{M})$, and the used dosage of JPB adsorbent was $0.4 \mathrm{~g} / \mathrm{L}$. The adsorption amounts for different solution $\mathrm{pH}$ values are presented in Fig. 10., and the results revealed that the adsorption amount of lead ions on JPB increased with the $\mathrm{pH}$ increased from 2.0 to 6.0. When the $\mathrm{pH}$ was lower, the solution contained a large amount of hydrogen ion $\left(\mathrm{H}^{+}\right)$and hydronium ion $\left(\mathrm{H}_{3} \mathrm{O}^{+}\right)$groups, and these groups competed for the fixed adsorption sites with $\mathrm{Pb}(\mathrm{II})$, resulting in fewer lead ions being adsorbed on the JPB. 

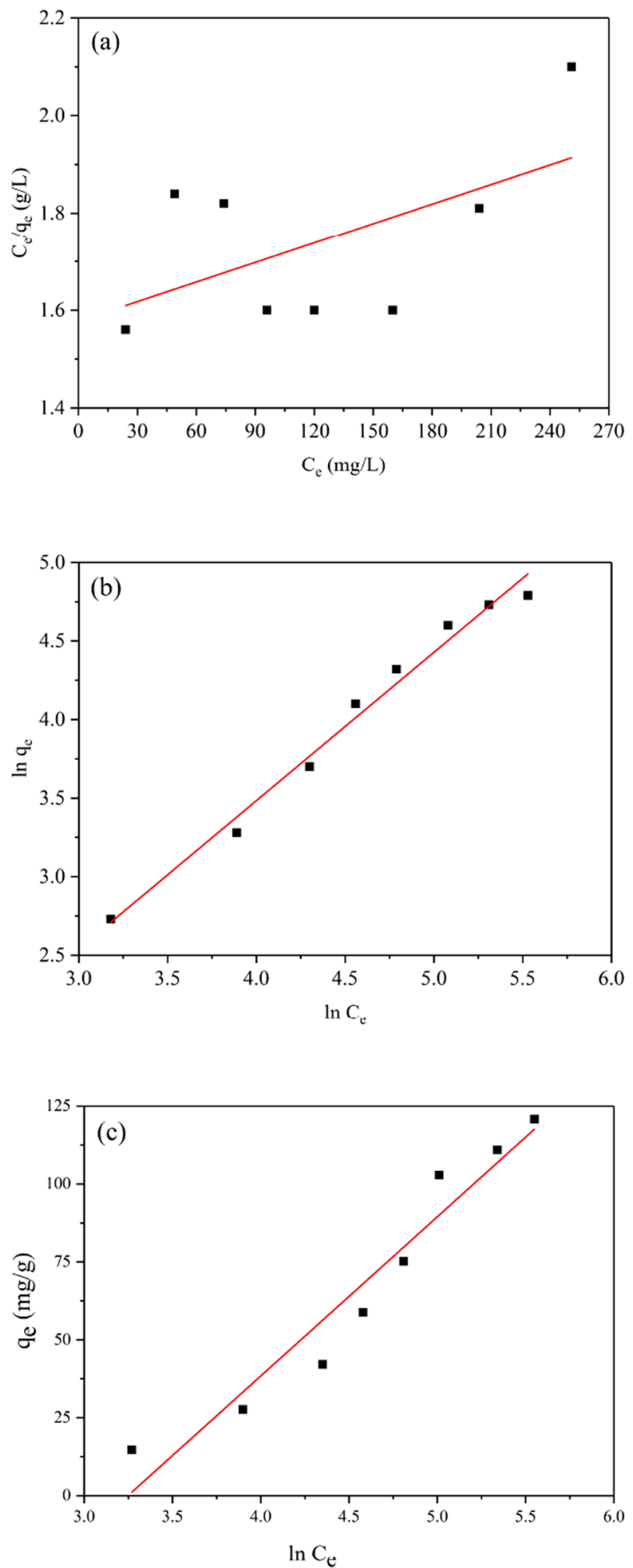

Figure 9. Langmuir isotherm model plot (a), Freundlich isotherm model plot (b) and Tempkin isotherm model plot (c) for $\mathrm{Pb}(\mathrm{II})$ sorption on JPB.

Moreover, because a repulsion effect occurs between cationic compounds, the hydrogen ion $\left(\mathrm{H}^{+}\right)$and hydronium ion $\left(\mathrm{H}_{3} \mathrm{O}^{+}\right)$groups distributed on the JPB surface would repulse the lead ions and make it away from the JPB surface $e^{40}$. Hence, $\mathrm{Pb}$ (II) adsorption on JPB was restricted in strengthened acidic condition. With the acid of solution condition weakened, the concentration of hydrogen ions $\left(\mathrm{H}^{+}\right)$and hydronium ions $\left(\mathrm{H}_{3} \mathrm{O}^{+}\right)$decreased, and more suitable adsorption sites were exposed to lead ions, leading to improved lead ion adsorption effectiveness by JPB. 


\begin{tabular}{|l|l|l|}
\hline Model & Parameter & Value \\
\hline \multirow{4}{*}{ Langmuir } & $\mathrm{K}_{\mathrm{L}}$ & 0.003629 \\
\cline { 2 - 3 } & $\mathrm{q}_{\mathrm{m}}(\mathrm{mg} / \mathrm{g})$ & 192.0 \\
\cline { 2 - 3 } & $\mathrm{R}^{2}$ & 0.3172 \\
\hline \multirow{4}{*}{ Freundlich } & $\mathrm{K}_{\mathrm{F}}$ & 0.7460 \\
\cline { 2 - 3 } & $\mathrm{q}_{\mathrm{m}}(\mathrm{mg} / \mathrm{g})$ & 137.1 \\
\cline { 2 - 3 } Tempkin & $\mathrm{R}^{2}$ & 0.9846 \\
\hline \multirow{5}{*}{} & $\mathrm{K}_{\mathrm{T}}(\mathrm{L} / \mathrm{mg})$ & 0.0592 \\
\cline { 2 - 3 } & $\mathrm{B}_{\mathrm{T}}$ & 33.71 \\
\cline { 2 - 3 } & $\mathrm{R}^{2}$ & 0.9249 \\
\hline
\end{tabular}

Table 2. The parameters of the adsorption isotherms of $\mathrm{Pb}(\mathrm{II})$ adsorption on JPB.

\begin{tabular}{|l|l|l|l|}
\hline Sample & $\mathbf{q}_{\mathbf{m}}(\mathbf{m g} / \mathbf{g})$ & Contacting time (min) & Reference \\
\hline $\mathrm{JPB}$ & 137.1 & 30 & Present work \\
\hline $\mathrm{WB}^{\mathrm{a}}$ & 87 & 60 & 46 \\
\hline $\mathrm{GB}^{\mathrm{b}}$ & 138.9 & 40 & 1 \\
\hline $\mathrm{RSB}^{\mathrm{a} 00^{\mathrm{c}}}$ & 144.3 & 360 & 22 \\
\hline $\mathrm{RPK}^{\mathrm{d}}$ & 128.1 & 470 & 25 \\
\hline $\mathrm{CABCU}^{\mathrm{e}}$ & 86.9 & 20 & 47 \\
\hline
\end{tabular}

Table 3. Comparison of adsorption capacities between JPB and other adsorbents. ${ }^{a} \mathrm{WB}$ : wheat bran. ${ }^{\mathrm{b}} \mathrm{RSB} 500$ : rice straw biochar. ${ }^{\mathrm{C}} \mathrm{RPK}$ : date palm rachis. ${ }^{\mathrm{d}} \mathrm{GB}$ : gingko leaf biochar. ${ }^{\mathrm{e}} \mathrm{CABCU}$ : calcium alginate beads of caryota urens.

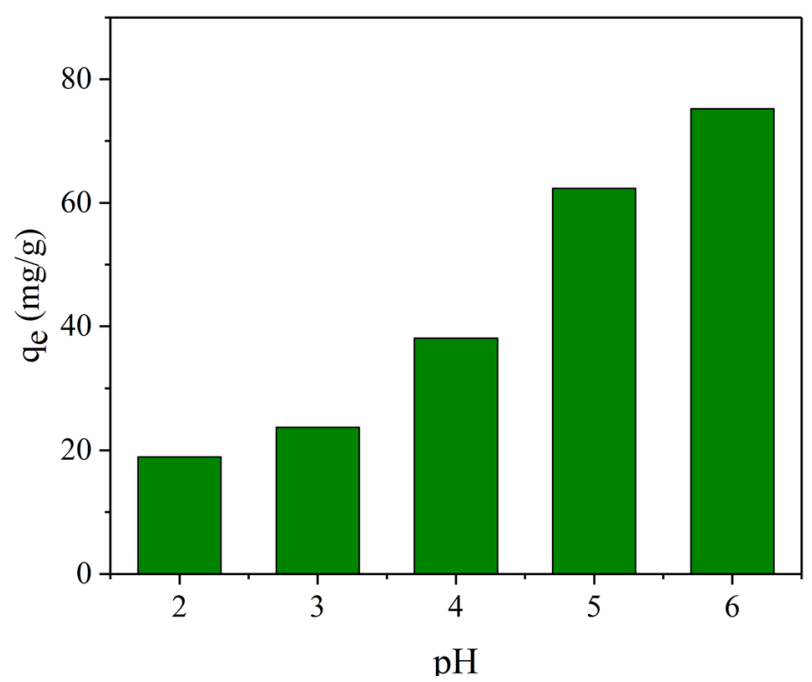

Figure 10. The capacity of lead ions for $\mathrm{pH}$.

Effect of $\mathrm{Na}^{+}$and $\mathrm{K}^{+}$. An investigation for the impacts of coexisting ions on lead ions adsorption was taken in this section. The examined data is available in Fig. 11., and the result showed that the $\mathrm{Na}^{+}$and $\mathrm{K}^{+}$had a slight influence of inhibition on the adsorption of lead ions, and the adsorption capacity of JPB for lead ions was slightly decreased with increasing the concentrations of coexisting ions; the slight inhibitory effect might be due to the competition of positive ions, $\mathrm{Na}^{+}\left(\mathrm{K}^{+}\right)$and $\mathrm{Pb}^{2+}$, for the active adsorption sites during the adsorption process ${ }^{11,41}$. However, divalent alkaline metal ions $\left(\mathrm{Pb}^{2+}\right)$ were favored over monovalent alkali metal ions $\left(\mathrm{Na}^{+}\right.$and $\left.\mathrm{K}^{+}\right)$in competition for the binding sites of $\mathrm{JPB}^{36}$. Therefore, the JPB developed in this study has great potential for actual applications.

Effect of temperature and adsorption thermodynamics. The relation of lead ion adsorption capacity by JPB for different temperatures in aqueous solution was investigated. The results of sorption capacity at different temperatures are exhibited in Fig. 12., and the adsorption capacity was approximately linear with temperature. The $\mathrm{Pb}$ (II) adsorption capacity on JPB was improved with the increase of temperature, which confirmed that the adsorption process of $\mathrm{Pb}(\mathrm{II})$ on $\mathrm{JPB}$ was endothermic. The adsorption thermodynamic parameters, such as free energy $(\Delta \mathrm{G})$, enthalpy $(\Delta \mathrm{H})$ and entropy $(\Delta S)$, were obtained according to Eq. $(9)^{42}$. 


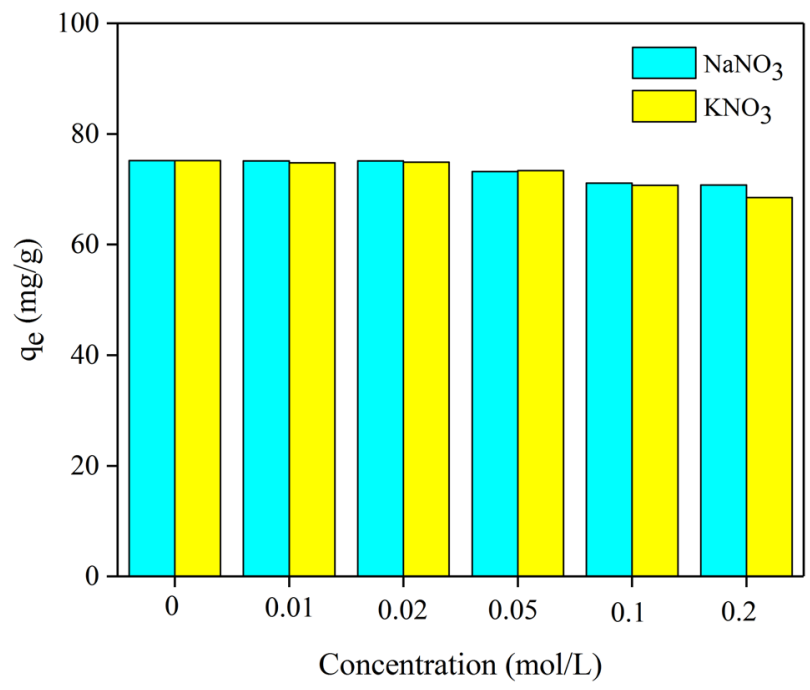

Figure 11. The adsorption of lead ions for JPB with $\mathrm{Na} / \mathrm{K}$ ions.

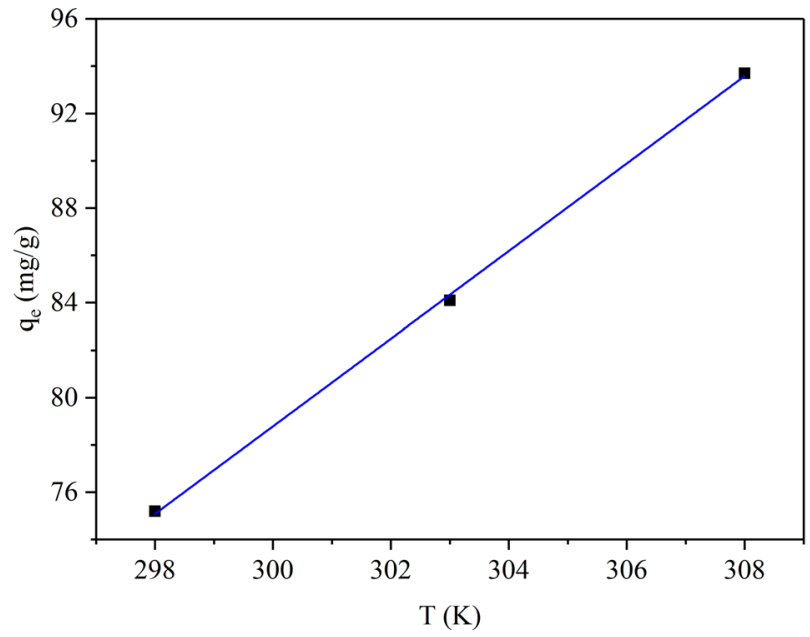

Figure 12. Effect of temperature on $\mathrm{Pb}(\mathrm{II})$ removal by JPB.

$$
\ln K_{d}=\frac{\Delta S}{R}-\frac{\Delta H}{R T}
$$

where $K_{d}$ refers to the adsorption distribution coefficient, T represents temperature $(K)$, and $R$ is the universal gas constant. The thermodynamic parameters $\Delta \mathrm{H}$ and $\Delta \mathrm{S}$ were determined according to the linear relation between $\ln K_{d}$ and $1 / T$ (Fig. 13.). The value of $\Delta G$ was obtained from Eq. $(10)^{42}$.

$$
\Delta G=\Delta H-T \cdot \Delta S
$$

The values of the relevant significant thermodynamic parameters $\Delta \mathrm{H}, \Delta \mathrm{S}$ and $\Delta \mathrm{G}$ are presented in Table 4 .

Because $\Delta \mathrm{H}$ was positive, the adsorption process was endothermic and the adsorption would be stimulated at a higher temperature to a certain extent ${ }^{43}$; furthermore, $\Delta \mathrm{S}$ with positive value reflected the random and disordered nature of the solid-solution interface during $\mathrm{Pb}(\mathrm{II})$ adsorption by $\mathrm{JPB}^{30}$. Moreover, the values of $\Delta \mathrm{G}$ for different temperatures were negative, which indicated that the adsorption experiment process could take place spontaneously ${ }^{30}$, and meanwhile, the negative values of $\Delta G$ were decreased with the solution temperature increasing, which showed that the process of lead ion adsorption in JPB was stimulated at elevated temperatures ${ }^{44,45}$.

Desorption and reusability. A reusable adsorbent could considerably decrease the operational cost of the purification of metal ions ${ }^{27}$. In the desorption and reusability test experiments, and the JPB was utilized five times. The adsorption capacity for each time is shown in Fig. 14., and it was obvious that the adsorption capacity of JPB still reached up to $70 \%$ of its initial adsorption capacity after five recycles, which illustrated that the recycled JPB 


\begin{tabular}{|l|l|l|l|}
\hline $\mathbf{T}(\mathbf{K})$ & $\Delta \mathbf{H}\left(\mathbf{k J} \cdot \mathbf{m o l}^{-\mathbf{1}}\right)$ & $\left.\Delta \mathbf{S}\left(\mathbf{J} \cdot \mathbf{m o l}^{-\mathbf{1}} \cdot \mathbf{K}^{-\mathbf{1}}\right)\right)$ & $\Delta \mathbf{G}\left(\mathbf{k J} \cdot \mathbf{m o l}^{-\mathbf{1}}\right)$ \\
\hline 298.0 & & & -28.99 \\
\hline 303.0 & 22.52 & 172.8 & -29.85 \\
\hline 308.0 & & & -30.72 \\
\hline
\end{tabular}

Table 4. The thermodynamic parameter values for $\mathrm{Pb}(\mathrm{II})$ adsorption by JPB.

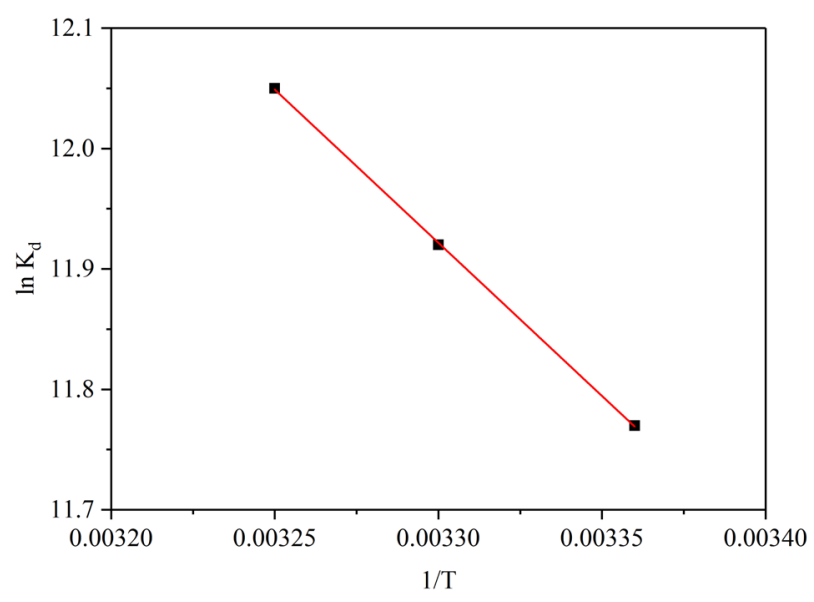

Figure 13. The linear graph of $\ln \mathrm{K}_{\mathrm{d}}$ versus $1 / \mathrm{T}$ for the adsorption of $\mathrm{Pb}(\mathrm{II})$ on $\mathrm{JPB}$.

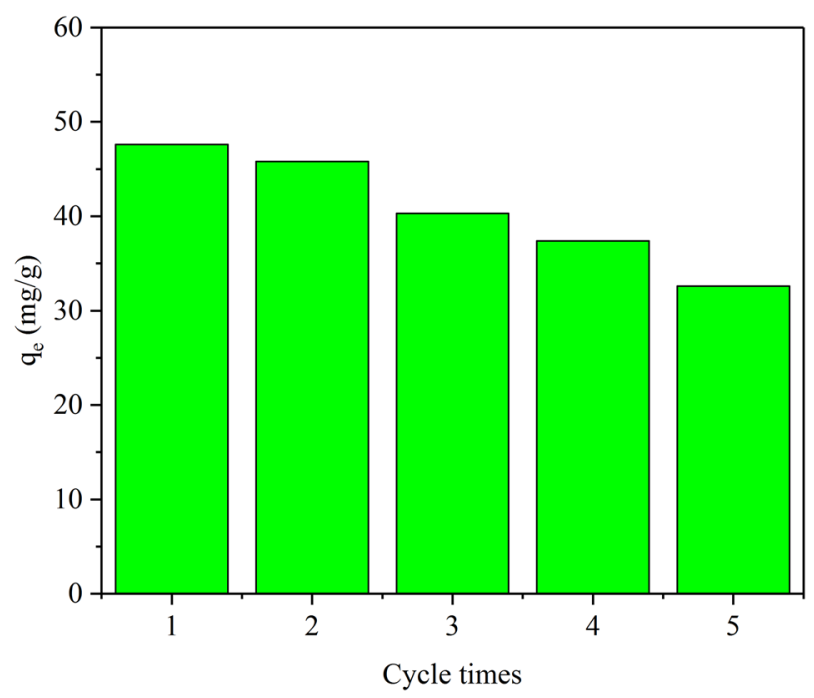

Figure 14. Adsorption capacity of $\mathrm{Pb}(\mathrm{II})$ by $\mathrm{JPB}$ for various recycling times.

adsorbent still possessed a relatively considerable adsorption capacity for $\mathrm{Pb}$ (II). Moreover, the adsorbed $\mathrm{Pb}$ (II) could be recycled as a precious metal resource. Hence, this JPB adsorbent, with properties of high efficiency and recyclability, is noteworthy for practical applications in lead ion removal and recovery from wastewater.

\section{Conclusion}

In this work, jujube pit biochar (JPB) was prepared using a simple and low-cost method, which could be used as an efficient material for lead ion removal. The nitrogen adsorption-desorption test results suggested that the JPB had large surface area, and under optimal conditions, the maximum adsorption amount of JPB for lead ions reached $137.1 \mathrm{mg} / \mathrm{g}$. Several adsorption behaviors were studied based on parameters in the adsorption process. And a significant improvement on adsorption capacity was determined by increasing the $\mathrm{pH}$, and the influence of coexisting ions, such as $\mathrm{K}^{+}$and $\mathrm{Na}^{+}$, was quite weak on the adsorption capacity of JPB. Moreover, the uptake capacity could reach equilibrium in $30 \mathrm{~min}$. Furthermore, the adsorption capacity of JPB still reached up to $70 \%$ 
of its initial adsorption capacity after five rounds of recycling, and the higher temperature could make a promotability for adsorption capacity. The study results demonstrated that JPB prepared from jujube pit possessed excellent adsorption ability for $\mathrm{Pb}(\mathrm{II})$ ions and had great potential for actual applications.

Received: 29 October 2019; Accepted: 7 April 2020;

Published online: 04 May 2020

\section{References}

1. Lee, M., Lee, J. H. \& Chung, J. W. Comparison of the lead and copper adsorption capacities of plant source materials and their biochars. J. Environ. Manage. 236, 118-124 (2019).

2. Naseem, R. \& Tahir, S. S. Removal of $\mathrm{Pb}$ (II) from aqueous solution by using bentonite as an adsorbent. Water. Res. 35, 3982-3986 (2001).

3. Li, F. \& Ding, C. Adsorption of reactive black M-2R on different deacetylation degree chitosan. J. Eng. Fibers. Fabrics. 6, 25-31 (2011).

4. Gao, J. K. et al. Norepinephrine-functionalised nanofower-like organic silica as a new adsorbent for efective $\mathrm{Pb}$ (II) removal from aqueous solutions. Sci. Rep-UK 9(1), 1-10 (2019).

5. Mohammadi, T., Moheb, A., Sadrzadeh, M. \& Razmi, A. Modeling of metal ion removal from wastewater by electrodialysis. Sep. Purif. Technol. 41(1), 73-82 (2005).

6. Hargreaves, A. J. et al. Impacts of coagulation-flocculation treatment on the size distribution and bioavailability of trace metals $(\mathrm{Cu}$, $\mathrm{Pb}, \mathrm{Ni}, \mathrm{Zn}$ ) in municipal wastewater. Water. Res. 128, 120-128 (2018).

7. Rengaraj, S., Yeon, K. H. \& Moon, S. H. Removal of chromium from water and wastewater by ion exchange resins. J. Hazard. Mater. 87, 273-287 (2001)

8. Merganpour, A. M., Nekuonam, G., Tomaj, O. A., Kor, Y. \& Safari, H. Efficiency of lead removal from drinking water using cationic resin Purolite. Environmental Health Engineering And Management Journal J 2, 41-45 (2015).

9. Gao, J., Sun, S., Zhu, W. \& Chung, T. Chelating polymer modified P84 nanofiltration (NF) hollow fiber membranes for high efficient heavy metal removal. Water. Res. 63, 252-261 (2014).

10. Du, Y., Lian, F. \& Zhu, L. Biosorption of divalent $\mathrm{Pb}, \mathrm{Cd}$ and $\mathrm{Zn}$ on aragonite and calcite mollusk shells. Environ. Pollut. 159, $1763-1768(2011)$.

11. Gao, J.-K., Hou, L.-A., Zhang, G.-H. \& Gu, P. Facile functionalized of SBA-15 via a biomimetic coating and its application in efficient removal of uranium ions from aqueous solution. J. Hazard. Mater. 286, 325-333 (2015).

12. Demirbas, A. et al. Heavy metal adsorption onto agro-based waste materials: a review. J. Hazard. Mater. 157, 220-229 (2008).

13. Anam, M. \& Rais, A. Novel recyclable (Xanthan gum/montmorillonite) bionanocomposite for the removal of $\mathrm{Pb}$ (II) from synthetic and industrial waste water. Environ. Technol. Inno 11, 241-252 (2018).

14. Rais, A. \& Anam, M. Synthesis of Guar gum/bentonite a novel bionanocomposite: Isotherms, kinetics and thermodynamic studies for the removal of $\mathrm{Pb}$ (II) and crystal violet dye. J. Mol. Liq. 249, 805-814 (2017).

15. Ravenni, G. et al. Adsorption and decomposition of tar model compounds over the surface of gasification char and active carbon within the temperature range $250-800^{\circ} \mathrm{C}$. Appl. Energ. 241, 139-151 (2019).

16. Zheng, W.-H. et al. Activated carbon fiber composites for gas phase ammonia adsorption. Micropor. Mesopor. Mat 234, 146-154 (2016).

17. Zheng, Y.-N. et al. Influence of temperature on adsorption selectivity: Coal-based activated carbon for $\mathrm{CH} 4$ enrichment from coal mine methane. Powder. Technol. 347, 42-49 (2019).

18. Badmus, M. A. O., Audu, T. O. K., Anyata, B. U. \& Turk, J. Removal of Lead ion from industrial wastewaters by activated carbon prepared from periwinkle shells (Typanotonus fuscatus), Turkish. Journal of Engineering \& Environmental Sciences 31, 251-263 (2007).

19. Anam, M. \& Rais, A. A facile synthesis of Poly (methyl metha acrylate) grafted alginate @Cys-bentonite copolymer hybrid nanocomposite for sequestration of heavy metals. Groundwater for Sustainable Development, 8, 82-92.

20. Altenor, S. et al. Adsorption studies of methylene blue and phenol onto vetiver roots activated carbon prepared by chemical activation. J. Hazard. Mater. 165, 1029-1039 (2009).

21. Bardestani, R., Roy, C. \& Kaliaguine, S. The effect of biochar mild air oxidation on the optimization of lead(II) adsorption from wastewater. J. Environ. Manage. 240, 404-420 (2019).

22. Shen, Z.-T. et al. Effect of production temperature on lead removal mechanisms by rice straw biochars. Sci. Total. Environ. 655, 751-758 (2019)

23. Benturki, O. \& Addoun, F. Use of activated carbons for treatment of water polluted by the phenolic substances. Asian. J. Chem. 19(6), 4523-4532 (2007).

24. Bouras, H. D. et al. The use of an agricultural waste material from Ziziphus jujuba as a novel adsorbent for humic acid removal from aqueous solutions. J. Mol. Liq. 211, 1039-1046 (2015).

25. Daoud, M. et al. Removal of reactive dye (BEZAKTIV Red S-MAX) from aqueous solution by adsorption onto activated carbons prepared from date palm rachis and jujube stones. J. Mol. Liq. 243, 799-809 (2017).

26. Rais, A. \& Anam, M. Application of Xanthan gum/n-acetyl cysteine modified mica bionanocomposite as an adsorbent for the removal of toxic heavy metals. Groundwater for Sustainable Development 7, 101-108 (2018).

27. Guo, L.-M. et al. Hollow mesoporous carbon spheres-an excellent bilirubin adsorbent. Chem. Commun. 40, 6071-6073 (2009).

28. Li, Y.-H. et al. Adsorption of cadmium(II) from aqueous solution by surface oxidized carbon nanotubes. Carbon 41, 1057-1062 (2003).

29. Gong, J.-L., Zhang, Y.-L. \& Jiang, Y. Continuous adsorption of $\mathrm{Pb}(\mathrm{II})$ and methylene blue by engineered graphite oxide coated sand in fxed-bed column. Appl. Surf. Sci. 330, 148-157 (2015).

30. Zhang, $\mathrm{W}$. et al. $\mathrm{Pb}(\mathrm{II})$ and $\mathrm{Cr}(\mathrm{VI})$ sorption by biochars pyrolyzed from the municipal wastewater sludge under different heating conditions. Bioresource. Technol. 147, 545-552 (2013).

31. Fu, J.-W. et al. Adsorption of methylene blue by a high-efficiency adsorbent (polydopamine microspheres): Kinetics, isotherm, thermodynamics and mechanism analysis. Chem. Eng. J. 259, 53-61 (2015).

32. Chen, Y. et al. Dopamine functionalization for improving crystallization behaviour of polyethylene glycol in shape-stable phase change material with silica fume as the matrix. J. Clean. Prod. 208, 951-959 (2019).

33. Liao, P. et al. Adsorption of dyes from aqueous solutions by microwave modified bamboo charcoal. Chem. Eng. J. 195, 339-346 (2012).

34. Svenska, K. \& Lagergren, S. About the theory of so-called adsorption of soluble substances. Handlingar 4, 1-39 (1898).

35. Ho, Y., McKay, G., Wase, D. \& Forster, C. Study of the sorption of divalent metal ions on to peat. Adsorpt. Sci. Technol. 18, 639-650 (2000).

36. Fan, C.-Z. et al. Comparative and competitive adsorption of $\mathrm{Pb}(\mathrm{II})$ and $\mathrm{Cu}(\mathrm{II})$ using tetraethylenepentamine modified chitosan/ CoFe2O4 particles. J. Hazard. Mater. 326, 211-220 (2017).

37. Freundlich, H. Over the adsorption in solution. The Journal of Physical Chemistry 57, 385-471 (1906). 
38. Langmuir, I. The adsorption of gases on plane surfaces of glass, mica, and platinum. J. AM. Chem. Soc 40, 1361-1368 (1918).

39. Liu, Y., Fu, R.-Q., Sun, Y. \& Zhou, X.-X. Multifunctional nanocomposites Fe3O4@SiO2-EDTA for Pb(II) and Cu(II) removal from aqueous solutions. Appl. Surf. Sci. 369, 267-276 (2016).

40. Zhang, X.-Y., Huang, Q. \& Liu, M.-Y. Preparation of amine functionalized carbon nanotubes via a bioinspired strategy and their application in $\mathrm{Cu}(\mathrm{II})$ removal. Appl. Surf. Sci. 343, 19-27 (2015).

41. Kosa, S. A. et al. Removal of heavy metals from aqueous solutions by multi-walled carbon nanotubes modified with 8-hydroxyquinoline. Chem. Eng. J. 181, 159-168 (2012).

42. Wang, Y. et al. Removal of uranium(VI) from aqueous solution using iminodiacetic acid derivative functionalized SBA-15 as adsorbents. Dalton. T 43, 3739-3749 (2014).

43. Rais, A. \& Anam, M. Facile one pot synthesis of chitosan-iron oxide (CS Fe2O3) nanocomposite: Removal of Pb (II) and Cd (II) from synthetic and industrial wastewater". J. Clean. Prod. 186, 342-352 (2018).

44. Romero-Gonzalez, J., Peralta-Videa, J. R., Rodriguez, E., Ramirez, S. E. \& Gardeaorresdey, J. L. Determination of thermodynamic parameters of $\mathrm{Cr}(\mathrm{VI})$ adsorption from aqueous solution onto Agave lechuguilla biomass. J. Chem. Thermodyn. 37, 343-347 (2005).

45. Rodrigues, L. A., Maschio, L. J., da Silva, R. E. \& da Silva, M. L. C. P. Adsorption of Cr (VI) from aqueous solution by hydrous zirconium oxide. J. Hazard. Mater. 173, 630-636 (2010).

46. Yasemin, B. \& Zubeyde, B. Removal of $\mathrm{Pb}(\mathrm{II})$ from wastewater using wheat bran. J. Environ. Manage. 78, 107-113 (2006).

47. Sujitha, R. \& Ravindhranath, K. Removal of lead (II) from wastewater using active carbon of Caryota urens seeds and its embedded calcium alginate beads as adsorbents. J. Environ. Che. Eng. 6, 4298-4309 (2018).

\section{Acknowledgements}

This work was supported by the Fundamental Research Funds for Zhejiang Provincial Universities and Research Institutes (No. 2019JZ00002), Zhejiang Provincial Natural Science Foundation of China (No. LY18E060007), National Natural Science Foundation of China (No. 51606168) and Science and Technology Planning Project of Zhoushan of China (No. 2019C21007, 2018C21017).

\section{Author contributions}

J.K.G., Y.L. J.B.W. and Y.C. conceived the experiments. Y.L., J.K.G., X.B.L., and M.Y.Y. performed the experiments. J.K.G., Y.L., J.B.W. and Y.C. analyzed the experimental data. J.K.G. and Y.L. wrote the manuscript. J.K.G., Y.L., J.B.W. and Y.C. discussed the results. J.K.G., J.B.W. and Y.C. reviewed the manuscript.

\section{Competing interests}

The authors declare no competing interests.

\section{Additional information}

Correspondence and requests for materials should be addressed to J.W.

Reprints and permissions information is available at www.nature.com/reprints.

Publisher's note Springer Nature remains neutral with regard to jurisdictional claims in published maps and institutional affiliations.

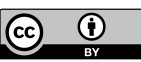

Open Access This article is licensed under a Creative Commons Attribution 4.0 International License, which permits use, sharing, adaptation, distribution and reproduction in any medium or format, as long as you give appropriate credit to the original author(s) and the source, provide a link to the Creative Commons license, and indicate if changes were made. The images or other third party material in this article are included in the article's Creative Commons license, unless indicated otherwise in a credit line to the material. If material is not included in the article's Creative Commons license and your intended use is not permitted by statutory regulation or exceeds the permitted use, you will need to obtain permission directly from the copyright holder. To view a copy of this license, visit http://creativecommons.org/licenses/by/4.0/.

(c) The Author(s) 2020 